\title{
Computer Simulations to Study the High-Pressure Deflagration of HMX
}

\author{
J.E. Reaugh
}

This article was submitted to American Physical Society Topical Conference on Shock Compression in Condensed Matter Portland, OR, July 20-25, 2003

\section{July 11, 2003}

U.S. Department of Energy

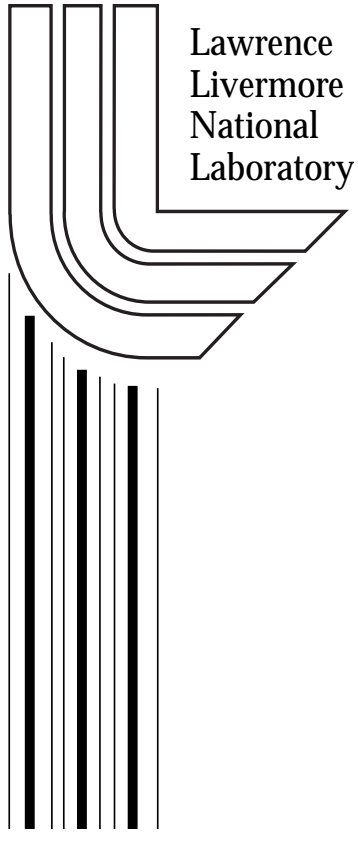




\section{DISCLAIMER}

This document was prepared as an account of work sponsored by an agency of the United States Government. Neither the United States Government nor the University of California nor any of their employees, makes any warranty, express or implied, or assumes any legal liability or responsibility for the accuracy, completeness, or usefulness of any information, apparatus, product, or process disclosed, or represents that its use would not infringe privately owned rights. Reference herein to any specific commercial product, process, or service by trade name, trademark, manufacturer, or otherwise, does not necessarily constitute or imply its endorsement, recommendation, or favoring by the United States Government or the University of California. The views and opinions of authors expressed herein do not necessarily state or reflect those of the United States Government or the University of California, and shall not be used for advertising or product endorsement purposes.

This is a preprint of a paper intended for publication in a journal or proceedings. Since changes may be made before publication, this preprint is made available with the understanding that it will not be cited or reproduced without the permission of the author.

This report has been reproduced directly from the best available copy.

Available electronically at http://www.doc.gov/bridge

Available for a processing fee to U.S. Department of Energy

And its contractors in paper from

U.S. Department of Energy

Office of Scientific and Technical Information

P.O. Box 62

Oak Ridge, TN 37831-0062

Telephone: (865) 576-8401

Facsimile: (865) 576-5728

E-mail: reports@adonis.osti.gov

Available for the sale to the public from

U.S. Department of Commerce

National Technical Information Service

5285 Port Royal Road

Springfield, VA 22161

Telephone: (800) 553-6847

Facsimile: (703) 605-6900

E-mail: orders@ntis.fedworld.gov

Online ordering: http://www.ntis.gov/ordering.htm

OR

Lawrence Livermore National Laboratory

Technical Information Department's Digital Library

http://www.llnl.gov/tid/Library.html 


\title{
COMPUTER SIMULATIONS TO STUDY THE HIGH-PRESSURE DEFLAGRATION OF HMX
}

\author{
John E. Reaugh \\ HE and Organics Group, Physics and Applied Technologies, Lawrence Livermore National Laboratory, \\ Livermore CA 94551
}

\begin{abstract}
The accepted micro-mechanical picture of the build-up of detonation in solid explosives from a shock is that imperfections are a source of hot spots. The hot spots ignite and link up in the reaction zone by high-pressure deflagration. Although the deflagration is subsonic, there are so many ignition sites that the pressure build-up is rapid enough to strengthen the initial shock. Quantitative advances in this research require a detailed understanding of deflagration at the high pressure, 1 to 50 $\mathrm{GPa}$, which is present in the reaction zone. We performed direct numerical simulations of highpressure deflagrations using a simplified global (3-reaction) chemical kinetics scheme. We used ALE3D to calculate coupled chemical reactions, heat transfer, and hydrodynamic flow for finite-difference zones comprising a mixture of reactants and products at pressure and temperature equilibrium. The speed of isobaric deflagrations depends on the pressure and initial temperature. We show how this dependence changes with kinetic parameters, including the order of the last reaction step and the heat of formation of the species formed, relative to the reactant.
\end{abstract}

\section{INTRODUCTION}

Starting in the 1940's, explosives researchers became aware of the safety hazards that resulted from the presence of 0.1 to $10 \mu \mathrm{m}$ gas bubbles or voids in solid and liquid explosives [1,2]. Such defects made the explosive more sensitive to shock. In the design of slurry explosives, defects are added to make the mixture detonable in the desired borehole diameter, but in solid and liquid explosives, they are reduced to minimize the sensitivity to handling accidents. In the reaction zone of a detonation, these voids become hot spots by their asymmetric collapse in the shock front. A deflagration starts at the hot spot and grows spherically until it begins to interact with the outward growing deflagrations from neighboring hot spots. Behind the deflagration front, the solid explosive crystal has transformed into gas products at high pressure and temperature.

We have used the computer hardware and software at our laboratory to study the details of the deflagration of high pressure and high-temperature explosives, as part of our Grain-Scale Dynamics in Explosives project for the Accelerated Strategic Computing Initiative. In the work reported here, we are using our computer simulations of deflagration to examine the dependence of the calculated deflagration speed on the chemical reaction kinetics and the species energetics.

\section{NUMERICAL METHODS}

We report the results of direct numerical simulations of deflagrations at high pressure. The computer simulation program, ALE-3D, which is 
under development at this laboratory, includes numerical methods to solve the heat flow equations either explicitly or implicitly. At present, the only solution method available for compressible hydrodynamic flow in the absence of shear strength is explicit. The resulting time step, as determined by the Courant condition for hydrodynamics [3] is larger than the explicit time step for heat transfer [3] for all mesh sizes $\square$ larger than the critical size $\square_{c}$, where

$$
\square_{c}=2 \square / c .
$$

Here $\square$ is the thermal diffusivity, and $c$ is the sound speed. Typical values for explosives and explosive products are $\square \sim 10^{-7} \mathrm{~m}^{2} / \mathrm{s}, c \sim 510^{3} \mathrm{~m} / \mathrm{s}$, so that $\square_{c}$ $\sim 0.04 \mathrm{~nm}$.

In standard solution methods for heat transfer, temperature is defined on the nodes of a finite element mesh. This is not directly compatible with standard solution methods for hydrodynamic flow in which all thermodynamic variables are defined within the volume of the finite element. Although methods have been developed to treat coupled, explicit hydrodynamics and heat transfer on the same mesh [4] the methods were not readily extended to include implicit heat transfer solutions. Instead, Nichols [5] developed a method that forces communication between the node-centered and element-centered temperature fields to have the appropriate time delay. This methodology was used for all the computer simulations reported here.

A challenging part of our numerical simulations is the incorporation of multiple chemical reactions using Arrhenius kinetics. Since the net result of these reactions is typically a $2500 \mathrm{~K}$ increase in temperature, the coupled equations become mathematically stiff. Nichols [6] developed a solution method that enforces simultaneous solution of pressure and temperature equilibrium for all species present in a finite element that is consistent with the chemical reaction rates. That method of coupling changes to species concentrations with temperature and hydrodynamics is used in all the simulations reported here.

In all of these simulations, we have ignored the contribution of species diffusion in smearing out the concentration of the intermediate products. The transport properties as calculated by Bastea [7] show that in the pressure range of interest to detonation, between 1 and $50 \mathrm{GPa}$, the ratio of species to temperature diffusivity changes from the lowpressure, ideal gas value of 1.0 to the high-pressure value of 0.01 . We can estimate the effect that change has on the calculated deflagration speed. Zel'dovich and Barenblatt [8] report a simplified set of equations for one-dimensional flame propagation where the ratio of species to thermal diffusivities is a parameter. For that case, the change in ratio from 1 to 0.01 results in a change of calculated flame speed of about a factor of four. From the solution of their equation set, our results will be qualitatively correct, but quantitatively in error. Some quantitative comparisons of our simulations with Diamond Anvil Cell (DAC) experiments in this pressure range have already shown that to be the case [9].

\section{MATERIAL PROPERTIES}

The review of Menikoff and Sewell [10] describes some of the properties needed for mesoscale simulations of explosives. They reported mainly the mechanical properties of the unreacted HMX explosive crystal. In addition, we need to describe the chemical reaction rates, and the mechanical, thermal, and transport properties of the various species present. We begin with the simplified global kinetics scheme reported by McGuire and Tarver [11] for HMX. That scheme includes a first, endothermic step, followed by a second, mildly exothermic step to form relatively highmolecular weight gas mixture, and a final exothermic step to form the final products. We identify the product of the first endothermic step as $\square$ HMX, although the endothermicity of Tarver's reaction scheme is significantly larger than the measured latent heat of the $\square-\square$ transition. We assumed that the intermediate gas products of the second step are those identified by Tarver: $\mathrm{CHOH}$, $\mathrm{N}_{2} \mathrm{O}, \mathrm{HCN}$, and $\mathrm{HNO}_{2}$.

We have taken the solid equation of state for the $\square$ - and $\square$-phase HMX to be simple MieGruneissen forms with constant specific heat. The compressibility of HMX is based on Yoo's DAC measurements [12]. We used Bridgman's correlation [13] for high-density fluids to estimate the pressure-dependent thermal conductivity. We constructed complete equation of state tables for the intermediate and final products using CHEQ [14]. 
Since exponential-6 potential parameters are not available for the intermediate products, they were estimated by Bastea based on results of classical MD simulations performed by $\mathrm{Wu}$ [15]. The transport properties for the two gas species are calculated by a method developed by Bastea [7] and incorporated as additional table entries.

\section{SIMULATION GEOMETRY AND BOUNDARY CONDITIONS}

The underlying simulation geometry is onedimensional slab symmetry, which is treated as a stack of cubes in ALE-3D. All four lateral faces are adiabatic symmetry planes. The material occupying the cubes is $\square$-HMX at the desired pressure, $p 0$, and at room temperature. The input boundary is held at the constant pressure $p 0$, and is given a temperature ramp from room temperature to the approximate flame temperature over a time of five (or sometimes ten) psec. The flame is propagated a distance of approximately one $\mu \mathrm{m}$, which is about half the initial length of the stack of cubes. At that time, typically $200 \mathrm{nsec}$, the propagation velocity is observed to be constant. Most of the simulations were performed with a cube dimension of four $\mathrm{nm}$, which results in an average time step of $0.5 \mathrm{psec}$, for a total of $0.6 \mathrm{M}$ calculational cycles. A few simulations were performed with smaller mesh sizes ( 2 and $1 \mathrm{~nm}$ ) to confirm that convergence with zone size had been achieved. The simulations with nominal resolution take 15 to 20 hours each on a $400 \mathrm{MHz}$ SG workstation.

\section{RESULTS AND ANALYSIS}

Computer simulations of deflagration for the nominal set of properties are well-represented by the functional form

$$
v=A p^{n}
$$

where A takes the value 2.6 and $n$ takes the value 0.38 for pressure in GPa and propagation velocity measured in $\mathrm{m} / \mathrm{s}$.

We performed variations on the nominal properties to determine the effects of changes in them to the calculated deflagration speed. We altered the heat of formation for the product of the first, endothermic step from its nominal value of $420 \mathrm{~J} / \mathrm{g}$ relative to the heat of formation of the reactant, $\square$ -
HMX. For the cases where the heat of formation was taken to be 0 or $-420 \mathrm{~J} / \mathrm{g}$, the values of the burn rates were identical to within $0.2 \%$, which is the precision that we can extract the flame speed from the simulations. Changing the activation energy of the first reaction to $90 \%$ of the nominal value, and changing the frequency factor to $110 \%$ of the nominal value similarly had no affect on the calculated flame speed.

Changes to the energy of formation of the intermediate products had a noticeable effect. Increasing (or decreasing) the heat of formation by $420 \mathrm{~J} / \mathrm{g}$ from the nominal value of $-540 \mathrm{~J} / \mathrm{g}$ relative to $\square$-HMX had the effect of decreasing (or increasing) the burn velocity at all pressures by $10 \%$. The power-law dependence of the flame speed was not changed. Changing the kinetic parameters of the second reaction in a similar way to the way we changed them for the first reaction resulted in no change to the calculated flame speed.

In contrast, the heats of formation of the final product and the kinetic parameters to form the final product have a substantial effect on the calculated burn rate. Reducing the heat of formation of the final product from $-6000 \mathrm{~J} / \mathrm{g}$ relative to $\square$-HMX to -6400 increases the flame speed by $18 \%$ at all pressures. Increasing the heat of formation to $-5600 \mathrm{~J} / \mathrm{g}$ reduces the velocity to $85 \%$ of the nominal value at all pressures. Reducing the activation energy of the last step by $10 \%$ increases the velocity to $145 \%$ of nominal at all pressures. Increasing the frequency factor by $10 \%$ increases the burn velocity at all pressures to $195 \%$ of nominal. We changed the order of the third reaction from second to first order. The pressure dependence of the flame speed changed from $n=$ 0.38 to $n=0.20$. Figure 1 shows the effect of changes to the final reaction on the flame speed.

\section{CONCLUSIONS}

The results of our simulations show that only those parameters associated with the substantially exothermic step have a significant influence on the propagation speed of high-pressure deflagrations. Reducing the activation energy or increasing the frequency factor of the exothermic reaction makes the temperature gradient steeper, which is associated with faster flame propagation. Decreasing the 


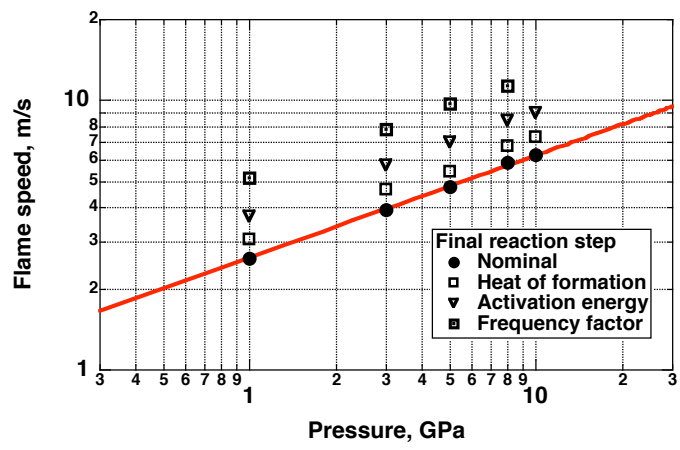

Figure 1. Calculated isobaric flame sped as a function of pressure for various perturbations to the nominal properties of the exothermic reaction step. The activation energy and frequency factor were changed $10 \%$, and the head of formation of the final products was reduced $7 \%$.

heat of formation of the final product results in an increase of the final temperature. At $10 \mathrm{GPa}$, for example, the flame temperature increases from the nominal value of 2820 to $2960 \mathrm{~K}$. This temperature rise, in turn, affects the kinetic rates as well.

\section{ACKNOWLEDGEMENTS}

The author has benefited greatly from the ALE 3D models for chemistry and heat transfer devised and implemented by Albert L. Nichols, and for his advice on their effective use. In addition, it is a pleasure to acknowledge the contribution of Sorin Bastea in developing and implementing consistent models of the transport properties of explosive products. The ALE 3D computer program team, lead by Richard Sharp, has earned our gratitude for having been so responsive to the needs of our project, and for implementing the changes to that program that we have requested. This work was performed under the auspices of the U.S. Department of Energy by University of California, Lawrence Livermore National Laboratory under Contract W7405-Eng-48.

\section{REFERENCES}

1. Bowden, F. P., and Yoffe, Y. D., Initiation and growth of explosion in liquids and solids, Cambridge University Press, Cambridge, 1952.
2. Campbell, A. W. et al., "Shock Initiation in Solid Explosives," The Physics of Fluids, vol. 4, no. 4, pp. 511-521, 1961

3. Richtmyer, R. D., and Morton, K. W., Difference Methods for Initial-Value Problems, second ed., John Wiley \& Sons, New York, 1967.

4. Reaugh, J. E., "Calculation of Quasistatic ElasticPlastic Deformation with Heat Conduction," Transactions, American Nuclear Society, vol. 18, p135136, 1974

5. Nichols, A. L., private communication on secondary zonal temperature method, Lawrence Livermore National Laboratory, 1999.

6. Nichols, A. L., private communication on the closely coupled hydro-thermal scheme, Lawrence Livermore National Laboratory, 2001.

7. Bastea, S., "Transport properties of fluid mixtures at high pressures and temperatures, Application to the detonation products of HMX," $12^{\text {th }}$ International Detonation Symposium, San Diego, CA, August 2002.

8. Zel'dovich, Ya. B. and Barenblatt, G. I., "Theory of Flame Propagation," Combustion and Flame, vol. 3, p61, 1959.

9. Esposito, A. P. et al., "Reaction propagation rates in HMX at high pressure," Propellants, Explosives and Pyrotechnics, vol. 28, no. 2, pp83-88, 2003.

10. Menikoff, R. and Sewell, T. D., "Constituent properties of HMX needed for mesoscale simulations," Combustion Theory and Modelling, vol. 6, no. 1, pp 103-125, 2002.

11. McGuire, R. R., and Tarver, C. M., "Chemical decomposition models for thermal explosion of confined HMX, TATB, RDX, and TNT explosives," $7^{\text {th }}$ Symposium (International) on Detonation, White Oak, MD, August 1976.

12. Yoo, C. -S. and Cynn, H., "Equation of state, phase transition, decomposition of $\square$-HMX (octahydro1,3,5,7-tetranitro-1,3,5,7-tetrazocine) at high pressures," Journal of Chemical Physics, vol. 111, no. 22, pp10229, 1999.

13. Bird, R. B. et al., Transport Phenomena, John Wiley, New York, 1960.

14. Ree, F. H. "A statistical mechanical theory of chemically reacting multiphase mixtures: application to the detonation properties of PETN," Journal of Chemical Physics, vol. 81, pp. 1251, 1984.

15. $\mathrm{Wu}, \mathrm{C}$. J., private communication, Lawrence Livermore National Laboratory, 2001. 